$\mathrm{E}$

EVALUAR
2019, Vol. 19, No. 1

ISSN 1667-4545

Recuperado de https://revistas.unc.edu.ar/index.php/revaluar

Laboratorio de Evaluación Psicológica y Educativa

Facultad de Psicología - Universidad Nacional de Córdoba

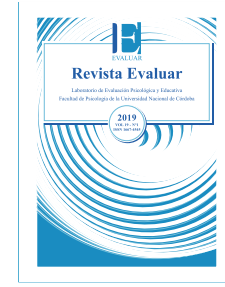

\title{
Motivational Regulation Strategies: A Questionnaire for its Measurement in Argentinian University Students
}

\author{
Estrategias de regulación motivacional: un cuestionario \\ para su medición en estudiantes universitarios argentinos
}

\author{
Javier Sánchez-Rosas * 1, Rocío Soledad Aguirre ${ }^{2}$, \\ Nicolás Bovina-Martijena ${ }^{2}$, Valeria Lucía Galarza ${ }^{2}$ \\ 1 - Laboratory of Psychological and Educational Assessment, Faculty of Psychology, National University of Cordoba, Argentina. \\ 2 - Faculty of Psychology, National University of Cordoba, Argentina.
}

Recibido: 10/11/2018 Revisado: 28/12/2018 Aceptado: 02/02/2019
Introduction

Study 1

Method

Results

Study 2

Method

Results

Discussion

References

\begin{abstract}
The objective of this work was to evaluate the psychometric properties of a modified version of the Motivational Regulation Strategies Questionnaire of Wolters and Benzon (2013) in a sample of Argentinian university students. Thirty bilingual students answered the instrument in English and Spanish and the equivalence of the translation was analyzed. Spearman's correlations between the original and the translated version were strong (.71 to .90$)$, which showed the equivalence. Then, the adapted questionnaire $(\mathrm{N}$ $=329$ ) was administered and its internal structure and internal consistency were analyzed. The exploratory factor analysis showed a questionnaire consisting of 37 items and eight factors. The scales showed good internal consistency indexes $(\alpha=.68$ to $\alpha=.95)$. The questionnaire evaluates value regulation, situational interest regulation, performance-approach regulation, performance-avoidance regulation, mastery-approach regulation, mastery-avoidance regulation, self-consequence, environmental structuring. The results and the need for new psychometric studies are discussed.
\end{abstract}

Keywords: regulation of motivation, self-regulated learning, motivation, task value, interest, achievement goals, measurement, university students

\section{Resumen}

El objetivo de este trabajo fue evaluar las propiedades psicométricas de una versión modificada del Cuestionario de Estrategias de Regulación Motivacional de Wolters y Benzon (2013) en una muestra de estudiantes universitarios argentinos. Treinta estudiantes bilingües respondieron al instrumento en inglés y español y se analizó la equivalencia de la traducción realizada. Las correlaciones de Spearman entre la versión original y la traducida fueron fuertes $(.71 \mathrm{a}$ .90), lo cual evidenció la equivalencia. Luego, se administró el cuestionario adaptado $(\mathrm{N}=329)$ y se analizaron su estructura y consistencia internas. El análisis factorial exploratorio evidenció un cuestionario conformado por 37 ítems y ocho factores. Las escalas mostraron índices de consistencia interna buenos $(\alpha=.68$ a $\alpha=.95)$. El cuestionario evalúa las regulaciones del valor, del interés situacional, de aproximación-rendimiento, de evitación-rendimiento, de aproximación-maestría, de evitación-maestría, auto-consecuencia y estructuración ambiental. Se discuten los resultados y la necesidad de nuevos estudios psicométricos.

Palabras clave: regulación motivacional, aprendizaje auto-regulado, motivación, valor de la tarea, interés, metas de logro, medición, estudiantes universitarios

How to cite: Sánchez-Rosas, J., Aguirre, R. S., Bovina-Martijena, N., \& Galarza, V. L. (2019). Motivational regulation strategies: A questionnaire for its measurement in Argentinian university students. Revista Evaluar, 19(1), 35-42. Recuperado de https://revistas.unc.edu.ar/index.php/revaluar

* Correspondence to: Javier Sánchez-Rosas, Enrique Barros and Enfermera Gordillo, Código Postal 5000, Córdoba, Argentina. Tel: (+549) 3516298702.

E-mail: jsanchezrosas@psyche.unc.edu.ar 


\section{Introduction}

Most research on self-regulated learning has focused on cognitive and metacognitive strategies, and has barely addressed the way in which students regulate their motivation to cope with boredom, distraction or other motivational obstacles. Wolters (2003) has defined motivational regulation as the activity through which individuals decide to initiate, maintain or supplement their predisposition to start, focus on or complete a particular task or goal. It includes thoughts, actions or behaviors through which students act in order to influence their choices, their effort or persistence in academic tasks (Wolters, 2003). Some research (Grunschel, Schwinger, Steinmayr, \& Fries, 2016; Ljubin-Golub, Petričević, \& Rovan, 2019; Schwinger \& Otterpohl, 2017; Smit, de Brabander, Boekaerts, \& Martens, 2017; Wolters \& Benzon, 2013; Wolters \& Rosenthal, 2000) has found that the students who most frequently use motivation regulation strategies have motivationally more adaptive beliefs (e.g., lower procrastination, higher task value and effort, higher levels of self-efficacy, and greater emphasis on mastery goals).

Researchers have designed instruments that evaluate a wide variety of motivational regulation strategies (Cabanach et al., 2009; Kim, Brady, \& Wolters, 2018; Paulino, Sá, \& Lopes da Silva, 2015; Schwinger, Steinmayr, \& Spinath, 2009; Schwinger, von der Laden, \& Spinath, 2007; Suárez-Riveiro \& Fernández-Suárez, 2005; Suárez \& Fernández 2011; Teng \& Zhang, 2016; Wolters \& Benzon, 2013) based on which they conducted psychometric studies that showed their suitability for measuring strategies of motivational regulation. In order to contribute to studies on motivational regulation, and in absence of an instrument validated in Argentina, this paper evaluates the psychometric properties of a modified version of the Motivational Regulation Strategies Questionnaire of Wolters and Benzon (2013) for its use with university students.

\section{Evaluation of motivational regulation strategies}

Motivational regulation strategies are students' efforts to maintain or improve their motivation, which involve three phases necessary for effective and permanent self-regulation of motivation: knowledge, monitoring and control of motivation (Wolters \& Benzon, 2013). The first phase involves meta-level understanding of students that reflects their knowledge or beliefs about motivation. The second phase requires monitoring of one's level or state of motivation. Finally, the third phase involves intentional actions in progress to intervene and control one's motivation, effort, or persistence.

Using an open survey, Wolters (1998, 2003) revealed more than a dozen different strategies for the regulation of motivation. Subsequent research has divided these strategies into five groups of particular importance: environmental structuring, self-consequence, self-talk on performance and self-talk on mastery (Cooper \& Corpus, 2009).

In three subsequent studies, while replicating the findings of Wolters (Wolters, 1999; Wolters \& Rosenthal, 2000), Schwinger et al. (2007) have also identified strategies for environmental control, self-consequence, performance self-talk and master self-talk. A scale of improvement on general interest consistent with Wolters (1999) was supported in one of these studies, but in the two remaining studies, it was divided into separate scales; one focused on maintaining situational interest and another focused on regulating personal value or importance (Wolters \& Benzon, 2013). Based on the analysis of the open questions in the first of these studies, Schwinger et al. (2007) de- 
vised some new items and found support for additional strategies based on performance-avoidance goals and the establishment of approach goals.

These studies have identified a wide variety of regulatory strategies, which led Schwinger et al. (2007) and Wolters and Benzon (2013) to construct separate instruments that measure the use of motivational regulation strategies. Next, we will focus on the description and proposal of adapting the Motivational Regulation Strategies Questionnaire of Wolters and Benzon (2013), which was facilitated by one of its authors, who in turn authorized its adaptation.

\section{Motivational regulation strategies questionnaire}

The Motivational Regulation Strategies Questionnaire (Wolters \& Benzon, 2013) is a thirty-item instrument that measures six strategies of motivational regulation, and for which validity and reliability studies showed good psychometric properties. Specifically, evidence of internal structure was provided by exploratory factor analysis, criterion validity evidence through its relationships with motivational variables and internal consistency through Cronbach alpha coefficient.

These items were subject to exploratory analysis of principal components with oblimin rotation, providing strong support for the existence of six different types of strategies. These six factors together represented $69 \%$ of the total variance and the scales derived from each of them showed high reliability that went from $\alpha=.77$ to $\alpha=.91$. The bivariate correlations between the six strategies were positive and high $(r s \geq .50$, $p s<$ .01 ), but not high enough so as to indicate that the strategies overlap in a single underlying construct. Finally, regarding criterion validity evidence, on the one hand, positive relationships were found between the six scales and task value, self-effi- cacy, mastery goals, cognitive and metacognitive learning strategies and, on the other hand, negative relationships with procrastination and performance goals.

The set of strategies was constituted as follows: regulation of value, regulation of performance goals, self-consequence, environmental structuring, regulation of situational interest and regulation of mastery goals. The aim of regulation of value is to increase the value of the material to be studied or of the task at hand. To do this, the students focus on the relevance that the task to be completed may have for their personal lives and the usefulness of the materials. Regulation of performance goals encourages students to invoke their desire to do well on their exams or at classes in general, and to convince themselves to keep up their efforts and complete the task. Self-consequence is a prototypical way by which students regulate their motivation by self-managing the consequences of their own behavior, as well as identifying and administrating extrinsic reinforcements or punishments to achieve particular objectives associated with the accomplishment of a task. Environmental structuring refers to students' efforts to adapt the study environment in order to carry out their tasks, as well as to adapt themselves physically. Regulation of situational interest is about students' attempts to complete their courses in a more pleasant, fun manner or as if it were a game. And finally, regulation of mastery goals is intended to fulfill the desire to improve their understanding or to learn as much as possible (Wolters \& Benzon, 2013).

In the present work, a modified version of this instrument is adapted. Reference is made to a modified version in relation to the scales of regulation of achievement goals, given that the original instrument does not make a distinction of approach and avoidance between mastery goals and performance goals. Therefore, the version 
was adapted using the scales of regulation of value, self-consequence, environmental structuring and regulation of situational interest, and was complemented with scales of regulation of performance-approach goals, performance-avoidance goals, mastery-approach goals and mastery-avoidance goals, which this investigation will expand on. Through two studies, we sought to

(a) obtain a version translated into Spanish equivalent to the original version in English,

(b) analyze the internal validity of the instrument through exploratory factor analysis, and

(c) analyze the internal consistency through Cronbach's alpha coefficient.

\section{Study 1: Scale adaptation Method \\ Translation and equivalence analysis}

In the present work, a direct translation from English into Spanish was carried out by an official translator and the authors of this work. When doing the translation, attention was directed to the semantic and syntactic properties, as well as to all the variations necessary so as to be applied to the target population without losing its meaning. Special attention was paid to the items having a clear, precise and simple formulation, trying to maintain the meaning of the construct the original item intended to measure.

To provide evidence on the equivalence of the translated version, an equivalence analysis was carried out between both versions of the instrument. Hambleton (1994) pointed out that one of the methods for carrying out this type of analysis is the implementation of the tests in the original language and translated into a sample of bilingual subjects. Subsequently, it is necessary to analyze if there is a correlation between the results obtained from the two versions.

\section{Participants}

The sample consisted of thirty bilingual students of the Faculty of Languages of the National University of Cordoba in the fourth year of undergraduate studying English translation, teaching or licentiate, 28 women, 20 to 29 years old.

\section{Instrument}

Scales adapted from the Motivational Regulation Strategies Questionnaire (Wolters \& Benzon, 2013). For the measurement of motivational regulation strategies, four of the six scales of the Wolters and Benzon instrument (2013) were used in their original version. The students had to respond, in Spanish and English, to twenty items using a Likert scale ranging from 1 (Never) to 5 (Always). The scales employed were: regulation of value (e.g., I make an effort to relate what we're learning to my personal interests; $\alpha=.91$, 6 items), self-consequence (e.g., I promise myself I can do something I want later if I finish the assigned work now; $\alpha=.91,5$ items), environmental structuring (e.g., I change my surroundings so that it is easy to concentrate on the work; $\alpha=.77$, 4 items) and regulation of the situational interest (e.g., I make studying more enjoyable by turning it into a game; $\alpha=.88,5$ items).

\section{Procedure and data analysis}

The English version of the questionnaire was administered at the Faculty of Languages to thirty bilingual students. They were informed that participation was voluntary and that confidential treatment of the information was guaranteed. After one week, the Spanish version was administered to the same thirty students. The data was 
Table 1

Descriptive statistics of the scales and their correlations.

\begin{tabular}{lccccc}
\hline \multicolumn{1}{c}{ Scale } & $\begin{array}{c}\text { Spearman } \\
\text { coefficient }\end{array}$ & M Original & DS Original & M Adaptationn & DS Adaptation \\
\hline regulation of value & $.82^{* *}$ & 3.40 & 0.75 & 3.24 & 0.81 \\
$\begin{array}{l}\text { self-consequence } \\
\begin{array}{l}\text { regulation of } \\
\text { situational interest }\end{array}\end{array}$ & $.90^{* *}$ & 3.07 & 1.06 & 3.00 & 1.15 \\
$\begin{array}{l}\text { environmental } \\
\text { structuring }\end{array}$ & $.75^{* *}$ & 2.52 & 0.92 & 2.27 & 0.80 \\
\hline
\end{tabular}

Note. ${ }^{* *} p<.01$.

loaded and analyzed with SPSS 24 (IBM, 2016).

First, the total score of the scales was obtained (value regulation, self-consequence, situational interest regulation, environmental structuring) by adding and calculating the average of the individual items. Then, the analysis of the correlations between each scale of the original instrument with its adapted version was performed, using the Spearman correlation coefficient. According to Martínez-Ortega, Tuya-Pendás, Martínez-Ortega, Pérez-Abreu and Cánovas (2009), Spearman's correlations can be interpreted as scarce or none $(0$ to .25$)$, weak (.26 to .50$)$, moderate and high (.51 to .75 ), and between high and perfect (.76 to 1 ).

\section{Results}

The correlations between the original scales and the adapted scales were moderate and high. Table 1 shows the descriptive statistics of the scales and their correlations.

\section{Study 2: Psychometric properties of the modified version of the Motivational Regulation Strategies Questionnaire Method}

Participants

The sample consisted in 329 university students of the Faculty of Psychology (49\%) and of the Faculty of Exact, Physical and Natural Sciences $(51 \%)$ of the National University of Córdoba, selected by accidental non-probabilistic sampling. The participants were between 18 and 59 years old; $63 \%$ of the sample consisted of women.

\section{Instruments}

An important modification made to the original version was the discrimination of the dimensions of approach and avoidance in the strategies of regulation of mastery goals and performance goals and, therefore, the creation of new items to measure these dimensions. In writing the items of the new strategies, the format used and recommended by Elliot and Murayama (2008) for the measurement of achievement goals was respected. 
Motivational Regulation Strategies Question-

naire. The total set of strategies to be evaluated was made up of eight scales in the following fashion: regulation of value (e.g., I think up situations where it would be helpful for me to know the material or skills), self-consequence (e.g., I promise myself some type of a reward if I get my readings or studying done), environmental structuring (e.g., I try to get rid of any distractions that are around me), regulation of situational interest (e.g., I make doing the work seem enjoyable by focusing on something about it that is fun), regulation of performance-approach goals (e.g., I remind myself that my goal is to do better than others at exams and tasks), regulation of performance-avoidance goals (e.g., I remind myself that my goal is to avoid performing worse than other students), regulation of mastery-approach goals (e.g., I tell myself I should keep working just to learn as much as I can), regulation of mastery-avoidance goals (e.g., I am persuaded to continue studying because my goal is to avoid learning less than I could).

In turn, the response scale of 7 (original version) was modified to 5 points by replacing the expression not at all with never, and very often with always. Consequently, the students had to respond using a Likert scale that ranges from 1 (Never) to 5 (Always) to indicate how often they used each strategy.

\section{Procedure}

The instrument was administered through the online survey system LimeSurvey (Pérez, 2007) due to its practicality for this type of surveys. The data obtained were loaded into the statistical program IBM SPSS versión 24.0 (IBM Corporation, 2016), where the necessary statistical procedures were carried out to complete the objectives set out in this work.
Data Analysis

Prior to the central analysis, an initial exploration of all the items was carried out in order to evaluate the missing values, the univariate and multivariate atypical cases and the normal distribution (George \& Mallery, 2007). Atypical cases were identified by calculating the $z$ score for each variable $(z$ score $>3.29$ was considered atypical) and Mahalanobis distance $(p<.001$ was considered atypical).

An exploratory factorial analysis was carried out in order to identify the constructs that underlie the items of motivational regulation strategies. The factorial analysis guidelines recommended by Fabrigar, Wegener, MacCallum, and Strahan (1999) were followed. The maximum likelihood factor extraction method was used (Jöreskog \& Lawley, 1968) because it is believed to produce the best estimates of the parameters (Pedhazur, 1982). Since the strategies are interrelated, an oblique rotation method (promax) was used. Multiple criteria were used for the selection of the number of factors: (a) the Kaiser rule of eigenvalues greater than 1 (Kaiser, 1960), (b) the sedimentation graph (Cattell, 1966), and (c) the interpretation of the rotated factors.

Then the internal consistency was estimated by means of Cronbach's alpha coefficient, revealing to what extent the different items of a test measure the same variable. The criterion used was the following: .70 acceptable, .80 good, and .90 excellent (George \& Mallery, 2007).

\section{Results}

Once the adequacy of the collected data was revised, the descriptive statistics of mean, standard deviation and the skewness and kurtosis indices of each variable were calculated (Table 2). 
Table 2

Descriptive statistics.

\begin{tabular}{|c|c|c|c|c|c|c|c|}
\hline Scale & Items & Minimum & Maximum & M & SD & Skewness & Kurtosis \\
\hline \multirow{6}{*}{$\begin{array}{l}\text { Regulation } \\
\text { of value }\end{array}$} & 1 & 1 & 5 & 3.65 & 0.93 & -0.45 & -0.04 \\
\hline & 2 & 1 & 5 & 3.71 & 0.92 & -0.46 & -0.04 \\
\hline & 3 & 1 & 5 & 3.77 & 0.96 & -0.54 & -0.16 \\
\hline & 4 & 1 & 5 & 3.57 & 0.96 & -0.37 & -0.25 \\
\hline & 5 & 1 & 5 & 3.64 & 1.07 & -0.53 & -0.45 \\
\hline & 6 & 1 & 5 & 3.53 & 0.99 & -0.44 & -0.20 \\
\hline \multirow{5}{*}{$\begin{array}{l}\text { Self- } \\
\text { Consequence }\end{array}$} & 1 & 1 & 5 & 2.69 & 1.33 & 0.25 & -1.13 \\
\hline & 2 & 1 & 5 & 3.00 & 1.27 & -0.05 & -1.02 \\
\hline & 3 & 1 & 5 & 3.14 & 1.22 & -0.24 & -0.95 \\
\hline & 4 & 1 & 5 & 2.74 & 1.24 & 0.20 & -0.96 \\
\hline & 5 & 1 & 5 & 2.99 & 1.22 & -0.11 & -0.96 \\
\hline \multirow{4}{*}{$\begin{array}{l}\text { Environmental } \\
\text { Structuring }\end{array}$} & 1 & 1 & 5 & 3.36 & 1.03 & -0.17 & -0.66 \\
\hline & 2 & 1 & 5 & 3.35 & 1.09 & -0.14 & -0.81 \\
\hline & 3 & 1 & 5 & 3.19 & 1.18 & -0.23 & -0.84 \\
\hline & 4 & 1 & 5 & 3.70 & 1.15 & -0.77 & -0.14 \\
\hline \multirow{5}{*}{$\begin{array}{l}\text { Regulation of } \\
\text { situational } \\
\text { Interest }\end{array}$} & 1 & 1 & 5 & 1.76 & 0.97 & 1.23 & 0.93 \\
\hline & 2 & 1 & 5 & 1.79 & 0.99 & 1.19 & 0.73 \\
\hline & 3 & 1 & 5 & 2.15 & 0.99 & 0.51 & -0.45 \\
\hline & 4 & 1 & 5 & 2.31 & 1.01 & 0.38 & -0.48 \\
\hline & 5 & 1 & 5 & 2.72 & 1.01 & -0.03 & -0.46 \\
\hline \multirow{5}{*}{$\begin{array}{l}\text { Regulation of } \\
\text { Performance-approach } \\
\text { Goals }\end{array}$} & 1 & 1 & 5 & 2.08 & 1.26 & 0.88 & -0.41 \\
\hline & 2 & 1 & 5 & 1.98 & 1.13 & 1.03 & 0.15 \\
\hline & 3 & 1 & 5 & 1.79 & 1.14 & 1.37 & 0.82 \\
\hline & 4 & 1 & 5 & 1.98 & 1.14 & 1.02 & 0.11 \\
\hline & 5 & 1 & 5 & 1.71 & 1.09 & 1.51 & 1.37 \\
\hline \multirow{5}{*}{$\begin{array}{l}\text { Regulation of } \\
\text { Performance-avoidance } \\
\text { Goals }\end{array}$} & 1 & 1 & 5 & 2.04 & 1.23 & 0.95 & -0.18 \\
\hline & 2 & 1 & 5 & 1.93 & 1.11 & 1.08 & 0.34 \\
\hline & 3 & 1 & 5 & 1.83 & 1.17 & 1.34 & 0.79 \\
\hline & 4 & 1 & 5 & 1.88 & 1.14 & 1.19 & 0.43 \\
\hline & 5 & 1 & 5 & 1.81 & 1.10 & 1.34 & 1.01 \\
\hline \multirow{5}{*}{$\begin{array}{l}\text { Regulation of } \\
\text { Mastery-approach } \\
\text { Goals }\end{array}$} & 1 & 1 & 5 & 3.89 & 1.03 & -0.79 & 0.18 \\
\hline & 2 & 1 & 5 & 3.91 & 1.00 & -0.71 & 0.01 \\
\hline & 3 & 1 & 5 & 4.04 & 0.92 & -0.83 & 0.48 \\
\hline & 4 & 1 & 5 & 3.90 & 0.96 & -0.45 & -0.54 \\
\hline & 5 & 1 & 5 & 3.91 & 0.98 & -0.73 & 0.16 \\
\hline \multirow{5}{*}{$\begin{array}{l}\text { Regulation of } \\
\text { Mastery-avoidance } \\
\text { Goals }\end{array}$} & 1 & 1 & 5 & 3.11 & 1.29 & -0.21 & -0.97 \\
\hline & 2 & 1 & 5 & 3.06 & 1.28 & -0.19 & -0.94 \\
\hline & 3 & 1 & 5 & 3.29 & 1.29 & -0.50 & -0.76 \\
\hline & 4 & 1 & 5 & 3.06 & 1.30 & -0.20 & -0.99 \\
\hline & 5 & 1 & 5 & 3.12 & 1.33 & -0.31 & -1.01 \\
\hline
\end{tabular}


In general, the items presented values within the normal parameters since no skewness and kurtosis value greater than $+/-2$ were observed.

\section{Analysis of internal structure}

The exploratory factor analysis permitted the identification of eight factors that underlie the items of motivational regulation strategies. Table 3 shows the results of the exploratory factor analysis, the eigenvalues, variance percentages and factor loads.

Table 4 shows the descriptive statistics for each scale and the correlations between them.

Table 3

Exploratory factor analysis of the items of motivational regulation.

Ítems

2. I think about reading or studying what I was assigned because I am trying to avoid having a worse performance than other students.

$\begin{array}{llllllll}1 & 2 & 3 & 4 & 5 & 6 & 7 & 8\end{array}$

4. I think about making an effort because my goal is to avoid having a worse performance than other students.

.95

.92

5. I tell myself that I must continue studying because my goal is to prevent myself from doing worse than others in this area.

1. I remind myself that my goal is to avoid doing worse than other students.

3. I remind myself that my goal is to avoid doing worse than others at exams and tasks of this subject.

2. I think I should keep working because my goal is to avoid learning less than I could.

4. I am convinced of working hard because my goal is to avoid learning less than is possible.

3. I challenge myself to complete the work because my goal is to avoid not understanding of the material.

5. I tell myself that I should study since my goal is to avoid not mastering a large part of the material.

1. I am persuaded to continue studying because my goal is to avoid learning less than I could.

2. I make a deal with myself that if I get a certain amount of the work done I can do something fun afterwards.

3. I tell myself I can do something I like later if right now I do the work I have to get done.

5. I promise myself I can do something I want later if I finish the assigned work now.

4. I set a goal for how much I need to study and promise myself a reward if I reach that goal.

1. I promise myself some kind of a reward if I get my readings or studying done. 


\begin{tabular}{rlllllllll}
\hline Ítems & 1 & 2 & 3 & 4 & 5 & 6 & 7 & 8
\end{tabular}

3. I challenge myself to complete the work because my goal is to understand most of the material.

4. I am convinced of working hard because my goal is to learn as much as possible.

2. I think I should keep working because my goal is to learn as much as I can.

1. I am persuaded to continue studying because my goal is to learn as much as I can.

5. I tell myself that I should study since my goal is to master most of the material.

2. I think about reading or studying what I was assigned because I am trying to perform better than other students.

1. I remind myself that my goal is to perform better than other students.

3. I remind myself that my goal is to do better than others in exams and homework assignments.

4. I think about making an effort since my goal is to have a good performance in relation to other students.

5. I tell myself that I must continue studying because my goal is to do better than others in this area.

1. I make studying more enjoyable by turning it into a game.

2. I try to make a game out of learning the material or completing the assignment.

3. I make doing the work enjoyable by focusing on something about it that is fun.

4. I try to get myself to see how doing the work can be fun.

5. I think of a way to make the work seem enjoyable to complete.

2. I make sure I have as few distractions as possible.

1. I try to get rid of any distractions that are around me.

3. I change my surroundings so that it is easy to concentrate on the work.

4. I try to connect the material with something I like doing or find interesting,

3. I make an effort to relate what we're learning to my personal interests.

2. I try to make the material seem more useful by relating it to what I want to do in my life.

1. I think up situations where it would be helpful for me to know the material or the skills.

\begin{tabular}{lcccccccc}
\hline Eigenvalue & 7.85 & 5.38 & 3.94 & 2.65 & 2.40 & 2.03 & 1.46 & 1.15 \\
Percentage of variance explained $(72.63 \%)$ & 21.23 & 14.55 & 10.64 & 7.16 & 6.50 & 5.48 & 3.95 & 3.12 \\
\hline
\end{tabular}

Note. Item loadings below .30 are not shown. 1 = regulation of performance-avoidance goals, $2=$ regulation of mastery-avoidance goals, $3=$ self-consequence, 4 = regulation of mastery-approach goals, $5=$ regulation of performance-approach goals, $6=$ regulation of situational interest, $7=$ environmental structuring, 8 = regulation of value. * Items 5 and 6 of regulation of value and item 4 of environmental structuring were eliminated due to scores $<.30$. 
Table 4

Descriptive statistics and bivariate correlations of the scales.

\begin{tabular}{|c|c|c|c|c|c|c|c|c|c|}
\hline & & 1 & 2 & 3 & 4 & 5 & 6 & 7 & 8 \\
\hline 1 & Reg. of Value & - & & & & & & & \\
\hline 2 & Self-Consequence & .08 & - & & & & & & \\
\hline 3 & Environmental Structuring & .09 & $.14 *$ & - & & & & & \\
\hline 4 & Reg. of Situational Interest & $.16^{* *}$ & $.26^{* *}$ & $.12 *$ & - & & & & \\
\hline 5 & Reg. of Performance-approach Goals & .04 & $.18^{* *}$ & $.12 *$ & .02 & - & & & \\
\hline 6 & Reg. of Performance-avoidance Goals & .02 & $.21 * *$ & .06 & .09 & $.65^{* *}$ & - & & \\
\hline 7 & Reg. of Mastery-approach Goals & $.36 * *$ & .09 & $.16^{* *}$ & .05 & .06 & .02 & - & \\
\hline \multirow[t]{5}{*}{8} & Reg. of Mastery-avoidance Goals & $.18^{* *}$ & $.18^{* *}$ & $.11^{*}$ & $.12 *$ & .08 & $.26^{* *}$ & $.49 * *$ & - \\
\hline & $\mathrm{M}$ & 3.68 & 2.91 & 3.40 & 2.15 & 1.91 & 1.90 & 3.93 & 3.13 \\
\hline & SD & 0.67 & 1.10 & 0.82 & 0.80 & 1.00 & 1.05 & 0.81 & 1.15 \\
\hline & Skewness & -0.37 & -0.01 & -0.13 & 0.70 & 1.15 & 1.17 & -0.51 & -0.30 \\
\hline & Kurtosis & -0.07 & -0.93 & -0.48 & 0.29 & 0.63 & 0.61 & -0.10 & -0.67 \\
\hline
\end{tabular}

Note. $* p<.05 * * p<.01$.

\section{Reliability analysis}

Then, we can see the Cronbach's $\alpha$ score obtained for the different scales that make up the motivational regulation strategy questionnaire and how that coefficient varies if any of its items is excluded (Table 5).

As Table 5 shows, all the scales presented values between acceptable, good and excellent internal consistency (George \& Mallery, 2007), except for regulation of value whose marginally acceptable value $(\alpha=.68)$ can be considered adequate for research purposes. In addition, positive and high correlations are observed between the items and the total.

\section{Discussion}

The objective of this work was to evaluate the psychometric properties of a modified version of the questionnaire of motivational regulation strategies for use with Argentine university students. A direct translation of the original instrument from English to Spanish was carried out, its internal structure was analyzed through exploratory factor analysis, and its internal consistency was evaluated using the Cronbach's alpha coefficient. The objectives proposed were satisfactorily fulfilled, obtaining a questionnaire of 37 items, grouped into eight scales with adequate indices of internal consistency. Next, the results obtained are discussed.

\section{Equivalence analysis}

First, four of the six scales (regulation of value, self-consequence, environmental structuring and regulation of situational interest) developed by Wolters and Benzon (2013) were translated. In order to evaluate the equivalence between the English and Spanish versions of the selected scales, these versions were applied to a bilingual sam- 
Table 5

Item-Total Statistics.

\begin{tabular}{|c|c|c|c|c|}
\hline Scale & Items & $\begin{array}{c}\text { Corrected } \\
\text { Item-Total Correlation }\end{array}$ & $\begin{array}{c}\text { Cronbach's } \alpha \text { if Item } \\
\text { Deleted }\end{array}$ & Cronbach's $\alpha$ \\
\hline \multirow{4}{*}{ Regulation of value } & 1 & .34 & .69 & \multirow{4}{*}{.68} \\
\hline & 2 & .51 & .58 & \\
\hline & 3 & .48 & .60 & \\
\hline & 4 & .51 & .57 & \\
\hline \multirow{5}{*}{ Self-Consequence } & 1 & .75 & .91 & \multirow{5}{*}{.92} \\
\hline & 2 & .84 & .89 & \\
\hline & 3 & .79 & .90 & \\
\hline & 4 & .79 & .90 & \\
\hline & 5 & .80 & .90 & \\
\hline \multirow{3}{*}{ Environmental Structuring } & 1 & .59 & .65 & \multirow{3}{*}{.78} \\
\hline & 2 & .67 & .60 & \\
\hline & 3 & .52 & .84 & \\
\hline \multirow{5}{*}{$\begin{array}{l}\text { Regulation of } \\
\text { Situational Interest }\end{array}$} & 1 & .74 & .81 & \multirow{5}{*}{.86} \\
\hline & 2 & .72 & .82 & \\
\hline & 3 & .68 & .83 & \\
\hline & 4 & .69 & .83 & \\
\hline & 5 & .55 & .86 & \\
\hline \multirow{5}{*}{$\begin{array}{l}\text { Regulation of } \\
\text { Performance-Approach Goals }\end{array}$} & 1 & .81 & .90 & \multirow{5}{*}{.92} \\
\hline & 2 & .80 & .90 & \\
\hline & 3 & .83 & .89 & \\
\hline & 4 & .78 & .91 & \\
\hline & 5 & .75 & .91 & \\
\hline \multirow{5}{*}{$\begin{array}{l}\text { Regulation of } \\
\text { Performance-Avoidance Goals }\end{array}$} & 1 & .83 & .94 & \multirow{5}{*}{.95} \\
\hline & 2 & .88 & .93 & \\
\hline & 3 & .85 & .94 & \\
\hline & 4 & .89 & .93 & \\
\hline & 5 & .86 & .94 & \\
\hline \multirow{5}{*}{$\begin{array}{l}\text { Regulation of } \\
\text { Mastery-Approach Goals }\end{array}$} & 1 & .71 & .87 & \multirow{5}{*}{.89} \\
\hline & 2 & .76 & .85 & \\
\hline & 3 & .76 & .86 & \\
\hline & 4 & .76 & .85 & \\
\hline & 5 & .65 & .88 & \\
\hline \multirow{5}{*}{$\begin{array}{l}\text { Regulation of } \\
\text { Mastery-Avoidance Goals }\end{array}$} & 1 & .75 & .92 & \multirow{5}{*}{.93} \\
\hline & 2 & .85 & .90 & \\
\hline & 3 & .82 & .91 & \\
\hline & 4 & .85 & .90 & \\
\hline & 5 & .78 & .92 & \\
\hline
\end{tabular}


ple. Subsequently, Spearman correlations were estimated with satisfactory results. The high correlations obtained between the variables of both versions ( $\rho$ between .71 and .90 ) confirm that the original and the translated version are equivalent.

\section{Internal structure}

The two non-selected scales of the Wolters and Benzon (2013) instrument assess the regulation of goals based on the dichotomous goal model (Maehr \& Nicholls, 1980). Currently, the 2 x 2 model of achievement goals (Elliot, 1999) has a more complex development of goals that includes the approach-avoidance dimensions in the goals of mastery and performance. Accordingly, it was decided to develop items that would allow for the estimation of the regulation of the four goals of the 2 x 2 model of achievement goals (Elliot, 1999); and consequently, the internal structure of a set of items that sought to measure eight strategies of motivational regulation (regulation of value, self-consequence, environmental structuring, regulation of situational interest, regulation of mastery-approach goals, regulation of mastery-avoidance goals, regulation of performance-approach goals, regulation of performance-avoidance goals).

The internal structure of the instrument was made up of the eight expected factors and 37 items. Items 5 and 6 of regulation of value and 4 of environmental structuring presented low correlations with their respective factor, so they were eliminated, improving the factorial structure of the instrument. In the original instrument, these items also charged lower than the rest of the items in their respective scales. The value regulation strategies point to the link of the task with a personal aspect (personal goals, usefulness for the fulfillment of personal achievements). The con- tent of item 5 of regulation of value does not explicitly show this link (I tell myself that it is important to learn the material because I will need it later in life) and this could be the reason for the low factorial load (.28). On the other hand, item 6 of regulation of value (I try to make myself see how knowing the material is personally relevant) presented a double factorial load on the factors regulation of value and regulation of mastery goals. The complexity of the writing of the item would lie in the fact that the act of knowing is a central aspect of the mastery goals while being relevant to the importance value of the learner. On the other hand, the low factorial load of item 4 of environmental structuring (I try to study at a time when I can be more focused) could be due to the fact that the regulation of the schedule does not necessarily imply regulation of the physical environment (visual, auditory stimuli). Added to this, the regulation of the environment may be more likely than the schedule, which is more subject to hourly availability, so that its covariation may be low.

\section{Internal consistency}

The results of internal consistency, evaluated by Cronbach's alpha coefficient, were good (George \& Mallery, 2007) and similar to those obtained in the original instrument (between .78 and .95). The scale of regulation of value showed a marginally acceptable value $(\alpha=.68)$, probably attributable to the small number of items. Further studies should consider the writing of additional and homogeneous items for an estimate that improves the internal consistency of the scale. In spite of this, the value obtained from internal consistency for the scale of regulation of value can be considered adequate for research purposes. 


\section{Limitations and future investigation}

There is a wide variety of motivational and affective constructs related to learning, performance (Eccles, 2005; Pekrun, 2006; Pintrich, 2003) and to which motivational regulation strategies would be related. Among these constructs are task value (Eccles, 2005), achievement goals (Elliot \& Murayama, 2008) and enjoyment (Pekrun, 2006). Considering that there are validated instruments for the evaluation of these constructs in Argentine university students, evidence could be provided of the relationship between the measurements made by the scales of this study and those made by the instruments that assess task value (Sánchez-Rosas, Lou, Lin, \& Larroza, 2017), achievement goals (Sánchez-Rosas, 2015a) and enjoyment (Sánchez-Rosas, 2015b).

On the other hand, it is important to mention that the sample was limited to university students of the Faculty of Psychology and the Faculty of Physical and Natural Sciences, 63\% women and $37 \%$ men. In future studies, it is suggested that the use of motivation regulation strategies be evaluated in students of other careers, and the possible differences be analyzed, in addition to conducting a study of gender differences in the use of the strategies. In turn, the same study could be conducted focusing on students of lower grades, since, in contrast, university students may be able to differentiate between concepts such as importance and interest and, therefore, distinguish the use of strategies designed to regulate every aspect of motivation.

The instrument studied here cannot be considered as an evaluation of all possible types of motivational regulation strategies. It is evident that there are important aspects of student motivation that are not well represented by the eight types of strategies evaluated with this instrument. For example, none of the strategies clearly reflects the efforts of students to strengthen or maintain their perceived competence or self-efficacy to complete their academic work. However, self-efficacy is a critical aspect of motivation and previous work has found some evidence of this type of regulatory strategy (McCann \& Turner, 2004, Wolters, 1998). Additional studies designed to discover and evaluate new strategies associated with these other forms of motivation represent another useful line of research.

On the other hand, in relation to the administered protocol, it is believed that the participants at the time of responding may not recognize differences between the items, due to the similarity in their content, as they are arranged according to the strategies. This could be considered a bias when measuring the strategies used. In future research, it is suggested that the items of different scales be interspersed and evaluated if there is a change.

The internal structure of the questionnaire is subject to the completion of a confirmatory factor analysis that provides evidence in favor of a model with the eight motivational regulation strategies identified in this exploratory study. As such, given the factorial loads and internal consistency values, it would be interesting to test the structure of an instrument with fewer items.

The availability of this instrument will lead to the measurement of motivational regulation in our context. For example, researchers interested in investigating the effects of programs aimed at developing self-regulated learning strategies, specifically motivational regulation, could perform pre-post measurements with this instrument. Or, how these strategies relate to other variables relevant to learning and academic performance could be explored. 


\section{References}

Cabanach, R. G., Valle, A., Gerpe, M. G., Rodríguez, S., Piñeiro, I., \& Rosário, P. (2009). Diseño y validación de un cuestionario de gestión motivacional. Revista de Psicodidáctica, 14(1), 29-47. Recuperado de http://www.ehu.eus/ojs/index.php/psicodidactica

Cattell, R. B. (1966). The scree test for the number of factors. Multivariate Behavioral Research, 1(2), 245276. doi: 10.1207/s15327906mbr0102 10

Cooper, C. A., \& Corpus, J. H. (2009). Learners' developing knowledge of strategies for regulating motivation. Journal of Applied Developmental Psychology, 30(4), 525-536. doi: 10.1016/j.appdev.2008.12.032

Eccles, J. S. (2005). Subjective task value and the Eccles et al. model of achievement-related choices. In A. J. Elliot \& C. S. Dweck (Eds.), Handbook of competence and motivation (pp. 105-121). New York: Guilford Press.

Elliot, A. J. (1999). Approach and avoidance motivation and achievement goals. Educational Psychologist, 34(3), 169-189. doi: 10.1207/s15326985ep3403_3

Elliot, A. J., \& Murayama, K. (2008). On the measurement of achievement goals: Critique, illustration, and application. Journal of Educational Psychology, 100(3), 613-628. doi: 10.1037/0022-0663.100.3.613

Fabrigar, L. R., Wegener, D. T., MacCallum, R. C., \& Strahan, E. J. (1999). Evaluating the use of exploratory factor analysis in psychological research. Psychological Methods, 4(3), 272-299. doi: 10.1037//1082-989x.4.3.272

George, D., \& Mallery, P. (2007). SPSS for Windows: Step by step 14.0 update $\left(7^{\text {th }}\right.$. ed.). Boston, MA: Allyn \& Bacon.

Grunschel, C., Schwinger, M., Steinmayr, R., \& Fries, S. (2016). Effects of using motivational regulation strategies on students' academic procrastination, academic performance, and well-being. Learning and Individual Differences, 49, 162-170. doi: 10.1016/j. lindif.2016.06.008
Hambleton, R. K. (1994). Guidelines for adapting educational and psychological tests: A progress report. European Journal of Psychological Assessment, 10, 229-244.

IBM Corporation (2016). IBM SPSS Statistics for Windows, Version 24.0 [Software de cómputo]. Armonk, NY: IBM.

Jöreskog, K. G., \& Lawley, D. N. (1968). New methods in maximum likelihood factor analysis. British Journal of Mathematical and Statistical Psychology, 21(1), 85-96. doi: 10.1111/j.2044-8317.1968.tb00399.x

Kaiser, H. F. (1960). The application of electronic computers to factor analysis. Educational and Psychological Measurement, 20(1), 141-151. doi: 10.1177/001316446002000116

Kim, Y., Brady, A. C., \& Wolters, C. A. (2018). Development and validation of the brief regulation of motivation scale. Learning and Individual Differences, 67, 259-265. doi: 10.1016/j.lindif.2017.12.010

Ljubin-Golub, T., Petričević, E., \& Rovan, D. (2019). The role of personality in motivational regulation and academic procrastination. Educational Psychology, 1-19. doi: 10.1080/01443410.2018.1537479

Maehr, M. L., \& Nicholls, J. G. (1980). Culture and achievement motivation: A second look. In N. Warren (Ed.), Studies in Cross-Cultural Psychology, (pp. 221-267), New York: Academic Press.

Martínez-Ortega, R. M., Tuya-Pendás, L. C., Martínez-Ortega, M., Pérez-Abreu, A., \& Cánovas, A. M. (2009). El coeficiente de correlación de los rangos de Spearman, caracterización. Revista Habanera de Ciencias Médicas, 8(2), 1-19. Recuperado de http://www. revhabanera.sld.cu/index.php/rhab

McCann, E. J., \& Turner, J. E. (2004). Increasing student learning through volitional control. The Teachers College Record, 106(9), 1695-1714. doi: 10.1111/j.1467-9620.2004.00401.x

Paulino, P., Sá, I., \& Lopes da Silva, A. (2015). Crenças e estratégias da motivação na aprendizagem: Desenvolvimento de uma escala. Psychologica, 58(1), 65- 
87. doi: 10.14195/1647-8606_58-1_4

Pedhazur, E. J. (1982). Multiple regression in behavioral research: Explanation and prediction $\left(2^{\text {nd }}\right.$. ed. $)$. Orlando, FL: Harcourt Brace.

Pekrun, R. (2006). The control-value theory of achievement emotions: Assumptions, corollaries, and implications for educational research and practice. Educational Psychology Review, 18(4), 315-341. doi: 10.1007/ s10648-006-9029-9

Pérez, C. J. M. (2007). Manual de Usuario de la plataforma de encuestas en línea: LimeSurvey. Versión 1.0, Licencia de Documentación Libre GNU.

Pintrich, P. R. (2003). A motivational science perspective on the role of student motivation in learning and teaching contexts. Journal of Educational Psychology, 95(4), 667-686. doi: 10.1037/0022-0663.95.4.667

Sánchez-Rosas, J. (2015a). Validation of the Achievement Goal Questionnaire-Revised in Argentinean university students (A-AGQ-R). International Journal of Psychological Research, 8(1), 10-23. doi: $10.21500 / 20112084.641$

Sánchez-Rosas, J. (2015b). The Achievement Emotions Questionnaire-Argentine (AEQ-AR): Internal and external validity, reliability, gender differences and norm-referenced interpretation of test scores. Revista Evaluar, 15(1), 41-74. Recuperado de https://revistas.unc.edu.ar/index.php/revaluar

Sánchez-Rosas, J., Lou, Y. C., Lin, H. F., \& Larroza, S. (2017). A Spanish version of the Achievement Task Value Scale for University Students: Internal, convergent, and criterion validity and reliability in Argentinian students. Pensando Psicología, 13(21), 41-57. doi: 10.16925/pe.v13i21.1713

Schwinger, M., \& Otterpohl, N. (2017). Which one works best? Considering the relative importance of motivational regulation strategies. Learning and Individual Differences, 53, 122-132. doi: 10.1016/j. lindif.2016.12.003

Schwinger, M., Steinmayr, R., \& Spinath, B. (2009). How do motivational regulation strategies affect achieve- ment: Mediated by effort management and moderated by intelligence. Learning and Individual Differences, 19(4), 621-627. doi: 10.1016/j.lindif.2009.08.006

Schwinger, M., Von der Laden, T., \& Spinath, B. (2007). Strategies zur Motivationsregulation und ihre Erfassung. Zeitschrift für Entwicklungspsychologie und Pädagogische Psychologie, 39(2), 57-69. doi: 10.1026/0049-8637.39.2.57

Smit, K., de Brabander, C. J., Boekaerts, M., \& Martens, R. L. (2017). The self-regulation of motivation: Motivational strategies as mediator between motivational beliefs and engagement for learning. International Journal of Educational Research, 82, 124-134. doi: 10.1016/j.ijer.2017.01.006

Suárez-Riveiro, J. M., \& Fernández-Suárez, A. P. (2005). Escalas de evaluación de las estrategias motivacionales de los estudiantes. Anales de Psicología, 21(1), 116-128. Recuperado de http://revistas.um.es/ analesps

Suárez, J. M., \& Fernández, A. P. (2011). Evaluación de las estrategias de autorregulación afectivo-motivacional de los estudiantes: Las EEMA-VS. Anales de Psicología, 27(2), 369-380. Recuperado de http://revistas.um.es/analesps

Teng, L. S., \& Zhang, L. J. (2016). Fostering strategic learning: The development and validation of the Writing Strategies for Motivational Regulation Questionnaire (WSMRQ). The Asia-Pacific Education Researcher, 25(1), 123-134. doi: 10.1007/s40299-015-0243-4

Wolters, C. A. (1998). Self-regulated learning and college students' regulation of motivation. Journal of Educational Psychology, 90(2), 224-235. doi: 10.1037/0022-0663.90.2.224

Wolters, C. A. (1999). The relation between high school students' motivational regulation and their use of learning strategies, effort, and classroom performance. Learning and Individual Differences, 11(3), 281-299. doi: 10.1016/s1041-6080(99)80004-1

Wolters, C. A. (2003). Regulation of motivation: Evaluating an underemphasized aspect of self-regulated learn- 
ing. Educational Psychologist, 38(4), 189-205. doi: 10.1207/s15326985ep3804_1

Wolters, C. A., \& Benzon, M. B. (2013). Assessing and predicting college students' use of strategies for the self-regulation of motivation. The Journal of Experimental Education, 81(2), 199-221. doi: 10.1080/00220973.2012.699901

Wolters, C. A., \& Rosenthal, H. (2000). The relation between students' motivational beliefs and their use of motivational regulation strategies. International Journal of Educational Research, 33(7-8), 801-820. doi: 10.1016/s0883-0355(00)00051-3 